\title{
Relato de Experiência no PIBID: Projeto interdisciplinar envolvendo Licenciandos em Computação e Pedagogia no Ensino Fundamental
}

\author{
Poliana Santos de Queiroz ${ }^{1}$, Higor R. Monteiro Santos ${ }^{1}$, Ariane Nunes Rodrigues ${ }^{1}$ \\ ${ }^{1}$ Universidade de Pernambuco, Campus Garanhuns (UPE) \\ CEP 55.294-902 - Garanhuns - PE - Brasil \\ poliana.santos.queiroz@gmail.com, \{higor.monteiro, ariane.rodrigues\} upe.br
}

\begin{abstract}
This paper aims to communicate the experience of a interdisciplinary project in the PIBID. In this project, undergraduates in Computer and Pedagogy worked collaboratively throughout 2015. Its application was carried out in a class of 6th grade of elementary school from a public school. According to the results, both the project coordinator as undergraduates had the opportunity to deal with the teaching challenges related computing, as a science, in basic education. Furthermore, this paper emphasizes the importance of PIBID in the formation of knowledge teachers needed educational practice of the stock even graduation.
\end{abstract}

Resumo. Este artigo tem como objetivo relatar a experiência de um projeto interdisciplinar vivenciado no Programa Institucional de Bolsas de Iniciação a Docência (PIBID). Nesse projeto, trabalhou-se de forma integrada os licenciandos em Computação e Pedagogia ao longo de 2015. Sua aplicação foi realizada numa turma do $6^{\circ}$ ano do Ensino Fundamental de uma Escola Municipal. De acordo com os resultados obtidos, tanto o coordenador do projeto quanto os licenciandos tiveram a oportunidade de lidar com os desafios docentes relacionados ao ensino de Computação, enquanto ciência na educação básica. Além disso, ressalta-se a importância do PIBID na formação dos saberes docentes necessários a prática educativa dos bolsistas ainda na graduação.

\section{Introdução}

A integração das Tecnologias Digitais da Informação e Comunicação (TDIC) dentro de espaços escolares tem fomentado discussões sobre novas práticas e métodos no processo de ensino e aprendizagem (FERREIRA et al., 2015). O Model Curriculum K-12 Computer Science $^{1}$, por exemplo, destaca que a maioria das profissões do século XXI exige uma compreensão da Ciência da Computação. Profissionais de arte, entretenimento, educação, comunicação, saúde, entre outros, precisam ter conhecimentos da Computação, enquanto ciência, na busca por soluções de problemas de áreas diversas, bem como na construção dessas soluções (FRANÇA et al. 2012).

Com isso, além da integração das tecnologias (computadores, celulares, tablets, etc.), torna-se relevante para os alunos das séries iniciais, o ensino de conceitos fundamentais da Ciência da Computação (NUNES, 2011). Esses conceitos propiciam o desenvolvimento de

\footnotetext{
${ }^{1}$ Disponível em: http://www.csta.acm.org/Curriculum/sub/CurrFiles/CSTA K-12 CSS.pdf
} 
habilidades que são exigidas no mundo atual, tais como, pensamento computacional, criatividade e raciocínio lógico. Habilidades estas que auxiliam na resolução de qualquer tipo de problema (NETO, SANTOS E SANTOS, 2015). No atual contexto educacional, é necessário repensar o papel do docente no que concerne o uso das TDIC como ferramenta pedagógica (BRANDÃO, SELVA E COUTINHO, 2006). Para tanto, a formação do professor deve estar elencada sobre as possibilidades e maneiras de se utilizar tais recursos em prol de uma prática pedagógica efetiva. Como constituinte das políticas públicas, o programa institucional de bolsas de iniciação à docência (PIBID) é uma iniciativa da Coordenação de aperfeiçoamento de pessoal de Nível Superior (CAPES) para os cursos de licenciatura do Brasil. O PIBID tem como principal finalidade instigar o licenciando a compreender o ambiente escolar e as possibilidades de atuar como docente de modo a valorizar a formação do mesmo. Implementado em nível nacional em 2007, o PIBID desenvolve desde então um papel fundamental e promissor para o desenvolvimento de práticas pedagógicas, como também promove uma melhoria da qualidade do ensino público.

Na Universidade de Pernambuco, o programa está em vigor desde 2011 em seus quatro campi, os quais concentram diversos cursos de licenciatura em todo o estado de Pernambuco. Sua estrutura possui subprojetos em áreas específicas e subprojetos interdisciplinares com a colaboração de várias áreas. Aquilo que se faz em cada subprojeto leva em consideração especificidades do contexto no qual a escola está inserida e o Projeto Político Pedagógico (PPP) para que assim o resultado do agir tenha significação. Nesse contexto, este trabalho se propõe a relatar a vivência de um subprojeto interdisciplinar com a integração de licenciandos de Computação e Pedagogia. As situações pedagógicas ligadas a essa experiência foram desenvolvidas numa turma do $6^{\circ}$ ano do Ensino Fundamental de uma Escola Municipal situada numa cidade do interior de Pernambuco.

\section{Trabalhos Relacionados}

Muitos trabalhos têm sido feitos na tentativa de inserir na educação básica os conceitos e práticas relacionadas ao ensino de Computação. Além disso, nos últimos anos é possível encontrar relatos de como o PIBID tem auxiliado os licenciandos em Computação nesse desafio. São descritos a seguir alguns trabalhos relacionados a este artigo publicados nos anos anteriores do Workshop de Informática na Escola (WIE).

Almeida e Carvalho (2012) demonstram, por meio de um estudo de caso, as possibilidades de oferecer através do curso de Licenciatura em Computação a formação técnica e pedagógica visando a implantação da tecnologia da informação nas escolas de educação básica para auxílio aos docentes de Física e Matemática. No ano seguinte, Almeida e Carvalho (2013) relataram a prática docente como componente curricular propiciando o uso das TDIC com perspectivas de melhoria nos processos de ensino e aprendizagem nas mais diversas áreas da informática bem como as contribuições do PIBID.

Na mesma linha, Marinho et al. (2015) abordam as ações desencadeadas no PIBID demonstrando a relevância do programa para a formação inicial dos professores na constituição dos saberes docentes necessários à atuação profissional. Lima e Sousa (2015) apresentam a experiência do curso ministrado por bolsistas do PIBID para alunos do ensino 
V Congresso Brasileiro de Informática na Educação (CBIE 2016)

Anais do XXII Workshop de Informática na Escola (WIE 2016)

médio de uma Escola Pública onde foi trabalhado a introdução ao raciocínio lógico, conceitos de algoritmo, estrutura sequencial e estrutura de seleção.

\section{Metodologia}

Desenvolvido entre março e dezembro de 2015, o projeto teve como intuito explorar e trabalhar recursos, conceitos e práticas computacionais para apoiar uma aprendizagem lúdica e efetiva no ambiente escolar. Ao longo de todo o projeto, houve a mediação de um professor da Rede pública de Ensino da microrregião de Garanhuns-PE, contemplados pelo Programa Institucional de Bolsas de Iniciação à Docência. O projeto foi organizado nas fases listadas a seguir:

1. Diagnose: além de observações nas turmas e na escola, foi realizada uma entrevista com o professor supervisor com o intuito de identificar pontos relativos e determinantes para o desenvolvimento do projeto;

2. Estrutura didática: foi pensado e planejado como aconteceriam as atividades de pesquisa e formulação de problemas, análise dos dados, construção de hipóteses, experimentação, avaliação e comunicação;

3. Elaboração de situações didáticas: o projeto direcionou-se para a elaboração de material didático, slides e escolha de softwares a ser utilizado no desenvolvimento do projeto;

4. Aplicação do projeto: entre março e dezembro de 2015 trabalhou-se em uma escola de rede pública do município de Garanhuns, com aproximadamente 35 alunos do $6^{\circ}$ ano do ensino fundamental;

5. Acompanhamento: ao longo de todo o projeto, a avaliação centralizou-se nas relações, conceitos e procedimentos estabelecidos pelos alunos do Pibid.

6. Elaboração de Relatório Técnico de Conclusão: a fase final do projeto consistiu na elaboração de um relatório para documentar as informações inferidas através da pesquisa e da experiência vivenciada

\section{Resultados e Discussão}

A estrutura do projeto interdisciplinar relatado neste artigo é composta por um professor supervisor da escola participante, quinze estudantes do curso de Licenciatura em Computação e três do curso de Pedagogia. Todo o projeto foi coordenado por um professor de Licenciatura em Computação. O campo de atuação em que foi vivenciado as atividades escolares configura-se em uma escola de rede pública municipal, localizada na cidade de Garanhuns- PE. As práticas docentes foram desenvolvidas em uma turma do $6^{\circ}$ ano do Ensino Fundamental com trinta e cinco alunos/as regularmente matriculados/as.

Nessa perspectiva, o projeto desenvolvido tentou enfatizar uma problematização que buscou nos alunos da escola a aprendizagem nos conceitos e práticas de Computação, enquanto ciência, de uma forma concreta para que o mesmo pudesse se tornar capaz de analisar os desafios e elaborar soluções do cotidiano. Num primeiro momento, foi realizada uma entrevista com o professor supervisor da escola e seus alunos. Em seguida, foi realizada a observação das aulas do docente colaborador com a intenção de identificar as principa is necessidades que permeavam o ambiente da escola. Diante disso, foi possível buscar formas adequadas e coerentes para mediar as aulas, onde os alunos puderam compreender e 
concretizar sua vivência acerca do conteúdo mediado. De acordo com o planejado na etapa 2, foram elaboradas atividades envolvendo o desenvolvimento do pensamento computacional, computação desplugada e softwares educacionais como SuperLogo ${ }^{2}$, Scratch $^{3}$ e RoboMind ${ }^{4}$.

Tomou-se como base o CsUnplugged ${ }^{5}$ para desenvolver atividades de computação desplugada. Os exercícios foram elaborados e desenvolvidos de acordo com o nível da turma e o contexto no qual os alunos estavam inseridos, onde o intuito era instigar a curiosidade e promover uma maior interação entre eles. Os conceitos e os softwares utilizados foram ministrados e instalados pelos licenciandos de Computação. Enquanto que os licenciandos em Pedagogia promoveram uma reflexão ao longo do projeto sobre os objetivos, meios e fins metodológicos, dando importância aos processos educativos que ocorrem dentro e fora do ambiente escolar. Dessa maneira, os futuros pedagogos atuaram como planejadores e dinamizadores de um ambiente de aprendizagem colaborativo.

Nesse contexto, tanto os licenciandos em Computação quanto os de Pedagogia foram inseridos no cotidiano escolar, tendo a oportunidade de experienciar metodologias e práticas docentes de caráter contemporâneo visando à superação de problemas identificados no processo de aplicabilidade do projeto. Após passar por esta experiência, alguns licenciandos expressaram seus sentimentos diante do projeto: Pibidiano 1: "Devido a troca de posição, tive uma visão de outro ângulo, podendo levar em consideração às dificuldades tanto dos alunos quanto as minhas como futuro professor". Pibidiano 2: "Aprendi a estar em uma sala de aula como educador e entendi que não basta apenas dominar o conteúdo, mas sim ter didática e acima de tudo paciência. Paciência no sentido de entender que cada um aprende de forma diferente".

Nesse sentido, os alunos puderam perceber durante o desenvolvimento do projeto uma vertente construtivista do ensino, vendo a inserção do ensino de Computação através de uma prática pedagógica renovada. Do ponto de vista do professor coordenador, " $O s$ licenciandos tiveram uma ótima experiência nesse projeto de forma a evoluírem tanto como estudantes quanto novos professores". De um modo geral, pode-se afirmar que os conteúdos e softwares foram bem aceitos pelos alunos da escola. Durante toda a aplicação do projeto, pôde-se notar o quanto os alunos estavam participativos, animados e satisfeitos com os conteúdos apresentados e práticas realizadas.

\section{Considerações Finais}

O PIBID tem fomentado nos últimos anos a formação docente dos estudantes de licenciatura em todo o Brasil. Dessa forma, é possível vivenciar novos processos formativos ao longo de toda a graduação, e não apenas ao seu final. Neste trabalho, foi relatada a experiência de um projeto interdisciplinar que envolveu licenciandos em Computação e Pedagogia. Do ponto de vista do coordenador de área, este projeto foi uma ótima oportunidade de introduzir

\footnotetext{
${ }^{2}$ Informações em http://www.nied.unicamp.br/?q=content/super-logo-30

${ }^{3}$ Informações em https://scratch.mit.edu/

${ }^{4}$ Informações em http://www.robomind.net/pt/

${ }^{5}$ Informações em http://csunplugged.org/
} 
conceitos e práticas de Computação na educação básica, estimular que licenciandos em Computação tenham uma reflexão pedagógica sobre o ensino e aprendizagem e proporcionar aos licenciandos em Pedagogia o uso e desenvolvimento de tecnologias a favor da educação.

Conforme o que foi evidenciado pelas falas dos licenciandos que atuaram no PIBID, pode-se dizer que o projeto teve resultados transformadores para os envolvidos. Além de terem tido a oportunidade de ministrar aulas e mediar o ensino e aprendizagem sobre os conceitos técnicos que estão aprendendo na graduação, eles também vivenciaram outras experiências. Tais como, ter mais responsabilidades sobre suas atividades docentes, ter mais sensibilidade para adequar os conteúdos de acordo com a realidade do ambiente em que estavam e a satisfação em ver os alunos aprenderem com suas aulas.

Como trabalhos futuros, pretende-se aplicar o projeto em outras escolas e realizar um trabalho de restauração dos laboratórios de informática para que as aulas sejam mais eficientes. Pois a maioria das escolas possuem laboratórios, mas não têm máquinas funcionando corretamente. Além disso, serão acrescentados novos conteúdos de Computação juntamente com novos softwares educativos, como light-bot, code.org e tryruby.

\section{Referências}

Almeida, C. e Carvalho, L. (2013) "Licenciatura em Computação: Práticas de Ensino e PIBID como aliadas do processo formativo". In: XIX Workshop de Informática na Escola (WIE, 2013).

Brandão, A., Selva, A., Coutinho, M. (2006) "O trabalho com projetos didáticos: integrando a leitura e a produção de textos". Belo Horizonte: Autêntica.

Ferreira, M. A.; Lima, J. S.; Santos, H. M.; Oliveira, E.; Nascimento, J. M. F. (2015) "Computação para Ensino Médio na Modalidade Semipresencial: Uma Experiência da Disciplina de Estágio Supervisionado”. In: Workshop de Informática na Educação (WIE, 2015).

França, R. S.; Silva, W. C.; Amaral, H. J. C. (2012) "Ensino de Ciência da Computação na Educação Básica: Experiências, Desafios e Possibilidades". In: XX Workshop sobre Educação em Informática (WEI, 2012).

Lima, A.; Souza, D. (2015) "Experiência no Programa Institucional de Bolsas de Iniciação à Docência (PIBID): Desenvolvimento do Raciocínio Lógico e Algoritmo na Educação Básica”. In: IV Congresso Brasileiro de Informática na Educação (CBIE, 2015).

Marinho, A. R. S.; Silva Junior, F. C.; Souza, G. R.; Morais, P. S. (2015) "Formação Inicial Docente em Questão: o PIBID na Licenciatura em Informática". In: Anais do XXI Workshop de Informática na Escola (WIE, 2015).

Neto, S.; Santos, H.; Santos, W. (2015) "ABILSEN: Uma Abordagem para Inclusão do Licenciado em Computação no Ensino Básico". In: Workshop de Educação em Informática, CSBC.

Nunes, D. (2011). "Ciência da Computação na Educação Básica”. Jornal da Ciência. 09 de setembro. 